Volume: 13 Issue: 1 Year: 2016

\title{
Consequences of child maltreatment in society and implementation of new prevention policies
}

\author{
Vedat Kargin ${ }^{1}$
}

\begin{abstract}
Child maltreatment is a global societal concern with serious consequences for all the nations. While severe child maltreatment catches the attention of child protection services and is brought up to the courts for punishment, there are hidden forms of abuse that are difficult to notice and hence, the predators of such offenses continue to violate the innocence of children over a long period of time. Turkey has to work twice as hard on this issue not only because of the structure of the child protection agencies but also because of the policies and strategies that are in need of revising so that the abusers will get the punishment that they deserve. In order to prevent child abuse it is vital to have parent education programs. This is simply because in our society parents usually see "spare the rod and spoil the child" as a philosophy in the child's upbringing. If the child is abused at home or by close relatives, a place of intervention might be the school environment. At child at school might exhibit aggressive behaviors or signs of abuse that should alert teachers and school administrators that abuse has taken place. If the educators suspect of abuse they should contact legal authorities to take legal action. Having an informed staff in school is only possible by having a school based intervention program. If the aim is to stop the abuse before it happens then the programs discussed in this paper is definitely a huge leap in the right direction.
\end{abstract}

Keywords: Child Maltreatment; Physical Abuse; Sexual Abuse; Emotional Abuse; Neglect.

\section{1-Introduction}

Child maltreatment is a global problem with serious long-term consequences to society and to the lives of maltreated children. In majority of cases, maltreatment occurs in forms of physical, sexual, emotional abuse and neglect for children under 18 years of age. According to World Health Organization statistics, 40 million children in the world between the ages of 1-14 suffer from abuse and neglect and need psychological support as a result (Simsek, Ulukol, \& Bingoler, 2004).

The issue of child maltreatment has a long history and unfortunately, in recent years the number of child maltreatment cases has been on the rise all around the world. According to recent statistics, in England 4 children die every week and in the United States of America (U.S.) 3 children die a day due to child maltreatment. Moreover, one child in a thousand under the age of 4 suffers physical abuse (Gumus, 2010). Child maltreatment and abuse is a global concern that has serious and devastating consequences for all societies. In Turkey, an abuse case was revealed by the media in which 45 children were raped by a single person. Similarly, in the U.S. a recent abuse case was uncovered in which "over many years hundreds of children have fallen victims to child predators wrapped in the authority and integrity of an honorable faith" as stated in grand jury report. These two similar events in socially two very different countries stress the importance of

\footnotetext{
${ }^{1}$ Ph.D., Turkish National Police, vedatkargin@yahoo.com
} 
Kargin, V. (2016). Consequences of child maltreatment in society and implementation of new prevention policies. International Journal of Human Sciences, 13(1), 1984-1996. doi:10.14687/ijhs.v13i1.3747

child maltreatment and abuse as a primal global societal concern and that something should be done promptly to stop it.

Very recently, multiple child abuse cases were exposed in Turkey which left us all stumped as a nation and once again draw public attention to prevention of child maltreatment and abuse in social institutions and in families. Despite being a paramount societal concern, there is a lack of knowledge regarding child maltreatment and its long-term consequences in Turkey. Therefore, this paper aims to introduce the concept of child maltreatment and contribute to the existing literature on the issue. More specifically, this paper highlights the relationship between childhood and maltreatment and how it is related to subsequent delinquency and/or adult criminality. In conclusion, this paper also proposes policy strategies that can be effective in preventing or at least reducing the number of child maltreatment cases.

For the purpose of this paper, a brief overview of the nature of the problem is presented; then, a theoretical basis of the relationship between childhood maltreatment and its long-term consequences are discussed; and past research on the issue is reviewed. Finally, to prevent and reduce childhood maltreatment and its negative consequences, two different intervention programs; a family and a school based program are proposed.

\section{2-The Scope of the Problem}

Child maltreatment is not a new phenomenon and continues to be a major problem for countries all around the world (Welsh et al., 2003). Child abuse and neglect may result in actual or potential harm to the children's physical and mental health, and development throughout their lives and increase risk for a variety of negative outcomes, such as delinquency and violence (Fergusson, Horwood, \& Lynskey, 1996; Fergusson \& Lynskey, 1997; Herrenkohl, Egolf, \& Herrenkohl, 1997).

However, little about its prevalence was known in the U.S. until the study by Kempe in 1962 which showed that child maltreatment rates were much higher than had been thought. In 1962, Kempe used the term "battered child" for the first time; later the term was replaced with the term "child abuse." Another study by Gelles and Straus (1979) collected survey data from a nationally representative sample of 2,143 American families measured the incidence of violence within the family. The findings pointed out that "between 1.4 and 1.9 million children in the U.S. were vulnerable to physical injury from their parents during the year of our study" (p.24).

Official data released by the U.S. Department of Health and Human Services also confirms that the child maltreatment problem cannot be underestimated. Such that, in 2000 , the data showed that about 879,000 children out of the 3 million child maltreatment cases reported to Child Protective Service agencies across the nation were victims of child maltreatment. Approximately $63 \%$ of these children were victims of neglect, $19 \%$ suffered from physical abuse, and $10 \%$ suffered from sexual abuse, and $8 \%$ suffered from psychological maltreatment. In majority of these cases, the children's parents $(78.8 \%)$ were the abusers. It was estimated that 1200 children lost their lives as a result of child maltreatment.

More recently, in 2008, an estimated 772,000 children were victims of abuse or neglect. Approximately $71.1 \%$ of these children suffered from neglect, $16.1 \%$ were abused physically, $9.1 \%$ were victims of sexual abuse, and $7.3 \%$ were psychologically abused. $80.1 \%$ of perpetrators of child maltreatment were parents. Approximately, 1,740 children died due to child abuse or neglect. (The National Child Abuse and Neglect Data System (NCANDS) Summary of Key Findings from Calendar Year 2000 and 2008. Report from the U.S. Department of Health and Human Services Administration for Children and Families.)

The rate of child abuse ranges $1 \%$ to $10 \%$ among countries globally, but in Turkey that range is $10 \%$ to $53 \%$ (Gumus, 2010). According to statistics provided by the Turkish Statistical Institute, a total of 188,044 children under the age of 18 came or were brought to law enforcement agencies within the year of 2010, increasing 35\% that number climbed up to 290,414 in 2014 . Of all children who came or were brought to law enforcement agencies, 83,393 children committed an offense in 2010 while 117,486 children committed an offense in 2014. A 40\% increase was 
Kargin, V. (2016). Consequences of child maltreatment in society and implementation of new prevention policies. International Journal of Human Sciences, 13(1), 1984-1996. doi:10.14687/ijhs.v13i1.3747

observed. The number of children who were victims of crime also increased $72 \%$ from 76,248 in 2010 to 131,172 in 2014 . Of 131,172 children who were victims of crime in 2014 , while $55.7 \%$ of the victims were male children, $44.3 \%$ of them were female children.

It is a known fact that Turkey is among the countries with higher rate of child maltreatment cases. There is a vast amount of child-oriented studies that have been conducted and the literature is well-established. However, when these studies are analyzed, it becomes evident that there is a lack of extensive and in-depth research data on child maltreatment in Turkey. Much more research is needed to examine and explore the scope and nature of the problem. Despite the shortage of scientific research on child maltreatment in the country, effective strategies which can lessen the devastating consequences of maltreatment will be proposed.

\section{3-Key Concepts (Defining Child Maltreatment)}

According to WHO, "child maltreatment is any type of act that may result in actual or potential harm to the child's health, survival, development of self-esteem or dignity in the context of a relationship of responsibility, trust or power." Child maltreatment is also referred to as child abuse and neglect. Maltreatment may occur in the forms of physical, sexual and emotional abuse, and neglect that result in actual or potential harm to the child's health, development or dignity (Sherwood, p. 127).

Child maltreatment includes all types of abuse and neglect of a child under the age of 18 by a parent, caregiver, or another person in a custodial role (e.g., clergy, coach, and teacher). Child abuse and neglect concepts are used interchangeably, but may occur in different forms of maltreatment. The U.S. federal law defines child abuse and neglect generally as, "any recent act, or failure to act, on the part of a parent or caretaker that results in death, serious physical or emotional harm, sexual abuse, or exploitation, or an act or failure to act that presents an imminent risk of serious harm to a child" (The Federal Child Abuse Prevention and Treatment Act (CAPTA) 42 U.S.C.A. $\$ 5106 \mathrm{~g})$.

Similarly, Turkish Criminal Law no:5237 Section Six Articles 102-105 define and regulate the offenses against sexual immunity including sexual abuse, child molestation, sexual intercourse between/with persons not attained the lawful age, and sexual harassment. Article 103 states, "Any person who abuses a child sexually is sentenced to imprisonment from three to eight years." Furthermore, in Turkish Criminal Law no: 5237, physical abuse is punishable by such offenses as voluntary manslaughter (article 81), felonious injury (article 86), negligent injury (article 89), torture (article 94), torment (article 96), threat (article 106) and cruelty (article 232). The punishment is much more severe if these offenses are committed against children or family members.

There are four common types of maltreatment: physical abuse, sexual abuse, emotional abuse, and neglect. While abuse occurs when either or both parents and/or caretakers use aggression against the child and may involve immediate medical treatment, neglect occurs when parents and/or caretakers deprive child from love, care, food, and health, which may also involve medical treatment.

\section{Physical abuse}

Physical abuse is a type of child maltreatment that is the most common and the easiest to identify among other types of abuse. Physical abuse involves incidents when the mother, father or the caregiver wants to punish the child for non-accidental reasons or when the child suffers injury as a result of parents' losing control or when accidents occur due to lack of parental care and supervision. Physical abuse might occur when physical force or violence against child is used by either or both parents and the caregiver. Physical abuse is defined as an act committed with the intention of physically hurting or inflicting physical harm to a child. Abuse may occur in the forms of beating, biting, shaking, throwing, stabbing, and burning (Gelles \& Straus, 1979). Beating is the most frequently used form of child abuse. Shaking is another form of physical abuse and is more frequently seen in the cases of children under 2 years old but this form of abuse can be seen in 
Kargin, V. (2016). Consequences of child maltreatment in society and implementation of new prevention policies. International Journal of Human Sciences, 13(1), 1984-1996. doi:10.14687/ijhs.v13i1.3747

children until 5 years old. Generally, such abuse occurs when a child (up to 15 months old) is severely shaken by the angry parents or the caregiver (Kara, Bicer \& Gokalp, 2004).

The children who suffered physical abuse have a higher rate of suicidal ideation and suicide attempts (Tackett, 2002). Victims of physical abuse, demonstrate remarkable social dysfunction, inadequacy, difficulty in establishing close relationships, anger and abuse-like behaviors (Tirasci \& Goren, 2007). For children who suffer from physical abuse and neglect it is fairly common to have cognitive ability disorders and be academically unsuccessful. A study reveals that neurologic disorders are seen at a higher rate in abuse victims (Gokler, 2002, Taner \& Gokler, 2004). Besides substance abuse, personality disorders, precarious sexual experiences, some psychiatric disorders such as, anxiety disorders, attention deficit disorders, hyperactivity, are things that are frequently encountered in child abuse and neglect cases (Gokler, 2002, Tackett, 2002, Taner \& Gokler, 2004).

According to the National Violence against Women Survey findings conducted from November 1995 to May 1996, physical abuse is widespread among adults in the United States: $51.9 \%$ of surveyed women and $66.4 \%$ of surveyed men said they were physically abused as a child by an adult caretaker and/or as an adult by any type of attacker (Tjaden \& Thoennes, 2000). According to Child Maltreatment Report of 2005, 16.6\% of the child maltreatment victims were physically abused.

According to the data provided by the Turkish Institute of Statistics, of 290,414 children who came or were brought to law enforcement agencies in 2014, 131,172 children, about 45.2\%, were victims of crime. Of those children who were the victims of crime, 74,087 children, approximately 56.7\%, suffered from physical abuse and 11.098 children, approximately 8.5\%, suffered from sexual abuse. Victimized children suffered from physical abuse the most and from sexual abuse the second. The official data show similar statistics for both male and female victims. As such, both male and female children suffered from physical abuse the most compared to other types of maltreatment discussed in this paper. A gender comparison of such offenses point out that $74.6 \%$ of male and $52.1 \%$ of female children were victims of physical abuse in 2014 .

\section{Sexual abuse}

Sexual abuse is a form of child abuse in which an adult or an older adolescent abuses a child for sexual stimulation. Such abuse occurs when an adult abuses a child who is underage and whose psycho-social development is incomplete. Child sexual abuse covers a wide range of sexual acts involving a child. It may include fondling, rape, molestation, and incest of a child by parents, caregivers, or friends (Finkelhor, 1994). This type of abuse has medical, social, legal and moral aspects. A survey on sexual abuse determined that until eighteen years old, $12 \%$ to $25 \%$ of girls and $8 \%$ to $10 \%$ of the boys were subjected to sexual abuse. Based on a compilation of surveys that identify the emotional and behavioral effects of sexual abuse on victims, children frequently exhibit fear reaction, anxiety, depression, anger, hostility and animosity, post-traumatic stress disorder and inappropriate sexual behavior (Kara, Bicer \& Gokalp, 2004).

According to Ministry of Justice statistics in Turkey, within the year of 2013 a total of 43,148 offenses against sexual immunity lawsuits were filed at courts under the Criminal Law articles 102-105. Of those offenses against sexual immunity, 17,948 offenses were for sexual abuse of children, which accounted for $41.6 \%$ of total offenses committed against sexual immunity. The official data indicated that the total number of sexual offenses committed towards children was 4,019 in 2003; in a decade that number increased more than 4 times as much and became 17,948 in 2013.

The statistics of Turkish Institute of Statistics show that approximately $8.5 \%$ of children who came or were brought to law enforcement agencies in 2014 suffered from sexual abuse. After physical abuse, sexual abuse was the second highest and most common childhood maltreatment type that was committed against children in Turkey. However, when gender is taken into consideration, girls are more likely to be victims of sexual abuse than boys. Statistics show that $19.2 \%$ of girls who are victims of crime suffer from sexual abuse whereas $2.2 \%$ boys who are victims of crime suffer from sexual abuse. 
Kargin, V. (2016). Consequences of child maltreatment in society and implementation of new prevention policies. International Journal of Human Sciences, 13(1), 1984-1996. doi:10.14687/ijhs.v13i1.3747

\section{Emotional abuse}

Emotional abuse involves engaging in behaviors, such as shaming, rejection, withholding love, and threatening that harm a child's self-worth or emotional well-being. According to Kara and et al. (2004), such abuse occurs when the children and the youth are deprived of tender loving care and attention that they need and suffer psychological and emotional damages when the void is not fulfilled. The abuser is one who has power over the child, usually is a member of the immediate family. Emotional abuse victims show signs of being distant from the family, being tense, develop feelings of unworthiness, social inadaptation and aggressive behavior. All the above mentioned behaviors can be seen accompanied by physical and sexual abuse and neglect or on its own by itself. Damages done by emotional abuse are as devastating as damages done by physical abuse (Kara, Bicer \& Gokalp, 2004). Unfortunately, there is not enough official data concerning emotional abuse as this type of abuse is usually very hard to detect and its traces are more easily hidden by the abuse victims or the abusers themselves. The researchers focusing on this type of abuse need to rely on their own data. Unfortunately there is no official data related to emotional abuse of children in Turkey.

\section{Neglect}

Neglect is the failure to meet a child's basic needs. These needs include housing, food, clothing, education, and access to medical care. (Please refer to Appendix 1 for more information regarding the behavioral indicators of child abuse and neglect). It can defined as responsible parents'/caregiver's neglect to provide a child's nutrition, health, shelter, clothing, protection and care that are vital necessities for a child's well-being. The umbrella term neglect also includes physical, emotional, educational and medical neglect. Especially with children who have growthdevelopment retardation, physical neglect is more frequent type of abuse compared to the other types discussed in this paper. Even though it is more commonly experienced than physical abuse, these types of cases are often ignored if they are not resulted in death or serious injury. This is simply because physical neglect is harder to identify compared to physical and sexual abuse. Damages caused by physical abuse can also be caused by physical neglect. The most important point separating physical abuse and neglect is that abuse is active and neglect is passive.

Turkish Ministry of Justice publishes annual statistics on juveniles received into law enforcement agencies of General Commandership of Gendarme and General Directorate of Police to determine the reasons and the size of juvenile delinquency in the country to be able to design preventive and protective policies for future juvenile delinquency. The data on children who came or were brought to law enforcement agencies because of an offense charge include information that may be considered as child neglect. These offenses charged by the law enforcement agencies are abandonment, street child, distuption of education, foundling, and street working:

Abandoned child who is left in a state of vulnerability and need by his/her parents or legal guardian. Street child who dwells/lives on the streets after leaving his/her residence because of reasons like poverty, family-breakdown, abuse and who is destitute of the protection of a parent or an elder in charge so that whose family bonds are gradually on the wane and who is vulnerable to abuse. Dismption of education: Child who is at the age of compulsory education but doesn't attend or is not allowed continuing his/her education whether he/she has a school enrollment. Foundling: Child about whom there is not any official application to a relevant authority because of the child's missing status and who is received into security unit after being found by a security unit or a citizen. Street working: Child who works on the street in a portion of the day to contribute to the family budget or to cover his/her expenses. According to this information and the official statics published by Turkish Statistical Institute, the number of children who were the victims of child neglect was 5,646 in 2010, decreasing to 4,100 in 2011, 4,461 in 2012, to 3.486 in 2013, and then reached at 5,641 in 2014. 
Kargin, V. (2016). Consequences of child maltreatment in society and implementation of new prevention policies. International Journal of Human Sciences, 13(1), 1984-1996. doi:10.14687/ijhs.v13i1.3747

\section{4-Criminological Issue}

Concern about child maltreatment has increased over the last three decades due to reports showing that large numbers of children are subject to abuse and neglect by their parents (Welsh et al. 2003). The concern is expanding not just because of the number of child maltreatment cases but also because of the long-term negative outcomes. Research on the issue has shown that child maltreatment has serious long-term consequences, such as physical, psychological, and behavioral consequences on the abused victims, which increased possibility of future delinquency and criminality (Huefner, Ringle, Chmelka, \& Ingram, 2007, Widom \& Maxfield, 2001, Pelcovitz, Kaplan, DeRosa, Mandel, \& Salzinger, 2000; Fergusson \& Lynskey, 1997).

Besides the physical injuries that are result of direct physical abuse, victims of child abuse are scarred for life psychologically and suffer from negative outcomes that prolong well into their adulthood. As Widom and Maxfield (2001) argue, violence produces violence and that today's abused children are high likely to involve in violence in the future. These children are at greater risk for experiencing a lack of self-control, higher levels of aggression and violence, academic and vocational problems, and substance abuse. Abused and neglected children may grow up to be abusive their own children and display suicidal behaviors compared to children who are not abused (Gelles \& Straus, 1979; Herenkohl et al., 2003; Fergusson \& Lynskey, 1997).

In addition to the direct consequences of child maltreatment, communities and government agencies experience many hardships caused by child maltreatment. They have to bear the greatest burden in responding to reports of child abuse. They have to shoulder financial, social, and other costs associated with child maltreatment including costs of hospitalization, child welfare, and mental health treatment, investigating child abuse reports, placing abused children in appropriate care, and taking legal action against the abuser (English, 1998; Malinosky-Rummel \& Hanen, 1993).

Unfortunately in Turkey, not only the abuse victim but also the victim's family or relatives tend to hide the abuse and the events leading to such a disgrace for a number of reasons. Such a tendency to hide the abuse undoubtedly hinders the victim to get the legal, medical, psychological and social support in order to cope with a life-scarring experience. The children who are victims of abuse are evaluated separately by criminal justice agencies and health organizations and their rights of privacy are violated. Furthermore, the workers in the above mentioned agencies do not have necessary educational proficiency to be able to take into account the victims mental and psychological status. That in fact, is something that accelerates the victim's trauma. For effective prevention of child maltreatment, and at the same time consciously and efficiently intervention to maltreatment victims, Child Monitoring Center (CMC) was established for the first time in 2012 within Ministry of Health. The most important aim of CMC is to prevent the second occurrence of abuse for children who have already been victims before and their protection. The center also aims to provide legal and medical procedures to victims by a properly educated and trained staff.

\section{5-Empirical Findings}

Parental conflict is one of the paramount reasons underlying child abuse and neglect. If children grow up experiencing this parental conflict, they are at a risk almost twice as much as the other children who do not experience such conflict. Furthermore those children are more likely to exhibit adjustment difficulties and become abusers in their future life. There is a vast amount of evidence to conclusively suggest that fact. In their comparative study, for example, Grych and Fincham reviewed 19 studies that examined the link between interparental conflict and the adjustment of children. 15 out of 19 studies found similar characteristics. Namely, children experiencing interparental conflicts in their childhood are at greater risk of adjustment difficulties. They concluded, "Recent research documents a modest but consistent relationship between interparental conflict and children's adjustment" (p. 269).

In parallel to the empirical findings, according to the Child Abuse and Domestic Violence Report of Turkey (2010), one of the main reasons of child abuse is the socio-economic status of the family. The parents who have participated in the study stated that their economic troubles were 
Kargin, V. (2016). Consequences of child maltreatment in society and implementation of new prevention policies. International Journal of Human Sciences, 13(1), 1984-1996. doi:10.14687/ijhs.v13i1.3747

reflected into the household and they usually took it out on the child. It is well established in the report that the in a traditional Turkish family, child is the first and mother is the second victim of abuse. The second reason of abuse in a Turkish family is the problems between the husband and the wife. Having a broken family, having a step parent are also among reasons of child maltreatment and abuse.

The link between victimization childhood abuse and subsequent delinquency is wellestablished in the past research. For example, Finkelhor et al., (1993) reviewed 45 studies and found children who were frequently and over long periods of time exposed to maltreatment were highest likely to experience long-term trauma, poor self-esteem, and be victims of crime. Within a Turkish context, studies or child abuse cases are not publicly available to researchers or policy makers. Therefore, as researchers, we have much as data to conduct our research and present concrete findings. Available data indicates that $20 \%$ of the women in Turkey have been victims of sexual abuse, whereas $\% 7$ of all males stated that they have been victims of abuse in their childhood at least once and the number of girls who have been victims of abuse and maltreatment are three times as much as the male victims. In Turkey, 56\% of the children between ages 7-18 have witnessed physical abuse, $49 \%$ have witnessed emotional abuse and 10\% have witnessed sexual abuse (p. 30)

While female children who were physically abused were more likely to become suicidal, female children who were sexually abused were more likely to commit prostitution than others. In addition, early childhood victimization of maltreatment can cause delinquency and criminality in the life course due to its consequences of mental health problems, educational difficulties, and employment problems (Estes \& Weiner, 2001 as cited in Welsh et al., 2003). Concordantly, Gutierres and Van Puymbroeck (2006) examined the link between female children exposed to maltreatment, adult violence and substance abuse. They reported that female victims of child abuse were found to have more tendencies towards substance abuse to cope with emotional and psychological consequences of stress and depression caused by maltreatment. Both childhood victimization of maltreatment and substance abuse increased odds of multiple forms of violence in adulthood.

Widom (1989) examined the relationship between child abuse and victims' subsequent criminality retrospectively employing a quasi-experimental research design. In the study abused participants were matched with non-abused participants in the control group. The aim was to understand whether victims of child maltreatment had differences in subsequent delinquency and criminality than the non-abused participants had tracking the participants' official criminal records from 1971 through 1988. The findings showed that there was a modest but statistically significant relationship between childhood maltreatment and subsequent delinquency and criminality. That is, abused and neglected participants had higher rates for adult criminality and arrests for violent offenses than did non-abused participants.

An updated study by Widom and Maxfield (2001) followed the same participants and reexamined their official criminal records 6 years later in 1994. This study found; (1) being abused or neglected as a child increased the likelihood of arrest as a juvenile by $59 \%$, as an adult by $28 \%$, and for a violent crime by 30 percent. (2) Maltreated children who were younger at the time of their first arrest, committed nearly twice as many offenses, and were arrested more frequently. (3) Physically abused and neglected (versus sexually abused) children were the most likely to be arrested later for a violent crime.

In another study, Pelcovitz et al. (2000) examined the relationship between childhood physical abuse and psychiatric diagnoses employing a quasi-experimental with multiple group design. Adolescents living in violent families were found to be at greater risk for depression, separation anxiety disorder, and post-traumatic stress disorder, than were physically abused adolescents living homes without violence. Participants in both experimental groups had significantly higher rates of diagnosis for a number of disorders, including major depression, conduct disorder compared to the participants in the comparison group. 
Kargin, V. (2016). Consequences of child maltreatment in society and implementation of new prevention policies. International Journal of Human Sciences, 13(1), 1984-1996. doi:10.14687/ijhs.v13i1.3747

As above reviewed studies have indicated, there is a continuum of violence that passes from abusive parents to child whose roots lie in childhood experiences of physical, emotional, and sexual abuse and neglect. From crime prevention perspective, it is important to recognize what these factors are and understand how they contribute to continuum of maltreatment and subsequent violence. If we have a better understanding of these factors, we can intervene and prevent/reduce child maltreatment and its negative and long-term effects on the lives of abused victims.

\section{6-Risk Factors for Child Abuse or Maltreatment}

Research has found a number of risk factors associated with child maltreatment. Children exposed to these factors are high likely to experience maltreatment and involve in future delinquency. These factors are classified to environmental and individual factors.

\section{Environmental Factors}

Coulton et al. (2007) reviewed 25 past studies on the relationships between neighborhood characteristics and child maltreatment. They found that child maltreatment cases were concentrated in disadvantaged and impoverished areas. The neighborhood characteristics included residential mobility, family disruption, and neighborhood socio-economic conditions (poverty, unemployment, and income level). However; they did not provide how these characteristics contributed to child maltreatment because these studies were correlation studies based on official data. Family structure variables, such as single parents, teen parents, family crowding are also related to child maltreatment (Coulton et al., 2000, Gelles \&Straus, 1979). Strain might be an explanation for the concentration of child maltreatment cases in these areas because people in the low socioeconomic and disadvantaged areas probably feel more and different types of strain than do people in other areas.

In another study Coulton et al, (1999) examined the relationships among neighborhood structure, process, and individual risk factors for child maltreatment from the perspectives of residents. They found that poverty and family disruption, substance abuse and stress, lack of moral and family values, and individual pathology accounted for almost two-thirds of the variance in the explanation of the causes of child maltreatment from the perspective of the residents. However, poverty and family structure accounted for the largest portion of the variance whereas individual risk factors, such as childhood history of abuse, accounted the least.

Research has shown that environmental and structural factors, such as family disruption, single or teen parents, poverty, and unemployment are related to child maltreatment. These factors affect family's overall risk of child maltreatment. For example, these factors may cause inadequate child health care and poor childrearing and parenting skills, which are associated with possibility of child abuse and neglect.

\section{Individual Factors}

Individual factors can be analyzed in two domains: child characteristics, which include age, disabilities; and parents' characteristics, which include parental history and the cycle of maltreatment, substance abuse, attitudes, knowledge, and age. For the purpose of this paper, parents' characteristics associated with child abuse are discussed.

As previously discussed, several studies (Gutierres \& Van Puymbroeck, 2006; Widom \& Maxfield, 2001; Pelcovitz et al., 2000; Finkelhor et al., 1993; Widom, 1989) found evidence supportive of the link between being abused as child and being abusive as adult. Sidebotham and Hweon (2006) examined multiple factors affecting the risk of maltreatment in young children through a longitudinal cohort research project. They found that young and undereducated parents with a history of childhood abuse were most likely to maltreat their children.

Jaudes et al. (1995) studied whether children who were born to mothers who used illicit drugs during pregnancy had been abused more or less during the study than were children from non-drug user mothers. Children whose parents used illicit drugs were found almost three times more likely to be abused and more than four times more likely to be neglected than were children whose parents did not use illicit drugs. Famulara, et al. (1992) also found that 72 percent of the 
Kargin, V. (2016). Consequences of child maltreatment in society and implementation of new prevention policies. International Journal of Human Sciences, 13(1), 1984-1996. doi:10.14687/ijhs.v13i1.3747

parents identified as child abuser from the records of juvenile court had abused alcohol and committed physical maltreatment of child.

Substance abuse may not be directly related to child maltreatment but indirectly. That is, some substances have stimulant effect whereas others have suppressive. Alcohol and drug abuse can affect parents' mental functioning and behavioral responses towards their children negatively and make maltreatment high likely. Alcohol and drug addiction can also cause parents to spend money to maintain their habits and cause neglect instead of meeting children's needs.

Parents' lack of or inaccurate knowledge about child's cognitive development and childrearing techniques can contribute to child maltreatment. These factors can bring about unrealistic behavioral expectations from child, inappropriate and harsh disciplining, and deprivation of love, health, and care.

\section{7-Policy Implications to Prevent Child Maltreatment}

As previously mentioned, children suffer from abuse in a family environment the most. Usually such factors as parental conflicts and/or having a step father or mother and socioeconomic or alcohol and drug use are contributors contribute to forming an abusive family environment. To improve the situation, the importance of good communication, listening to children, spending quality time as a family, being considerate and being a good role model should be stressed. It is also important for parents to understand that spare the rod you will spoil the child attitude should be left aside and children should not be beaten to be taught a lesson. Programs may occur in parents' homes, in schools, in medical or mental health clinics, or in other community settings. Although one on one or group sessions can be preferred in other countries, in Turkey one on one session might be better for families as they might not feel comfortable discussing their problems in front of other families.

\section{School-Based Prevention Program}

A school-based prevention program that targets those children who show indicators of childhood maltreatment is proposed. It aims to reduce the indicators of child maltreatment and to prevent subsequent violence. As Widom et al. (2006) points out, early aggressive behavior is one of the potential pathways between childhood maltreatment and subsequent violent behavior.

Within a Turkish concept an intervention program should aim to reduce or mediate aggression. Small children in elementary education will be identified. School administrators will be contacted to obtain information about the behaviors of these victims of abuse. Participants will be provided a one-year school-based educational and behavioral intervention that aims to improve the participants' knowledge about negative consequences of aggressive behavior and to teach cognitive coping mechanisms with aggression.

Furthermore, school teachers, administrators will be given a number of seminars that focus on early identification of abuse victims, how to approach abuse victims and handle the situation and report to proper authorities so that proper legal action can be taken against the abuser. Behavioral intervention will be conducted through professional consultants to improve behavioral responses in situations where aggression emerges.

The effectiveness of this program can be evaluated through an experimental design. Participants in the control group can be also selected from the victims of maltreatment but the treatment should not be presented in the control group. Although this design brings ethical questions to mind because it withholds desirable treatment in the control group, "solution to this dilemma is to interrupt an experiment if preliminary results indicate that a new program does in fact produce improvements in a treatment group" (Maxfield \& Babbie, 2005, p. 62). Therefore, if any improvement is observed in the behaviors of participants in the experimental group, the intervention should be interrupted and presented in the control group.

\section{Family-Based Intervention Program}

A family-based intervention program that aims to improve parents' attitudes towards infant and knowledge about child rearing is proposed to prevent/reduce future child maltreatment. 
Kargin, V. (2016). Consequences of child maltreatment in society and implementation of new prevention policies. International Journal of Human Sciences, 13(1), 1984-1996. doi:10.14687/ijhs.v13i1.3747

Studies showed that abused children are at a higher risk of being tomorrow's abusive parents than are non-abused children. Therefore, the proposed intervention targets those parents who are victims of maltreatment as children and have had a newborn infant. These parents will be provided an education and training program about effective childrearing practices and child developmental process to improve their attitudes and knowledge about parenting skills during their stay at the hospital. Also, these parents will be visited at their home three times on monthly basis after their discharge from the hospital and will be presented additional training about infant care at home.

The home visitations will be evaluated by properly educated and trained staff members for parents. The staff will also be interviewed every six months. If necessary, parents should be provided psychological support. On the other hand, children will go through doctor visitations every six months so that early signs of physical and behavioral maltreatment can be detected. Interrupted time series design may be utilized to evaluate the impact of the program. This research design enables researcher to assess the magnitude of the impact of the proposed program by including pre/post-intervention observations on child maltreatment cases. The official case reports should be utilized as much as possible for cases that are similar. Any difference or departure in the post-intervention observations from the counterfactual projected from pre-intervention observations will show the impact of the program. To increase the strength of the study, a nonequivalent no treatment control group may also be added based on the population, socioeconomic and family characteristic, and crime rates.

\section{8-Conclusion}

Child maltreatment is a global societal concern with serious consequences for all the nations. While severe child maltreatment catches the attention of child protection services and is brought up to the courts for punishment, there are hidden forms of abuse that are difficult to notice and hence, the predators of such offenses continue to violate the innocence of children over a long period of time. Turkey has to work twice as hard on this issue not only because of the structure of the child protection agencies but also because of the policies and strategies that are in need of revising so that the abusers will get the punishment that they deserve. In order to prevent child abuse it is vital to have parent education programs. This is simply because in our society parents usually see "spare the rod and spoil the child" as a philosophy in the child's upbringing. Parent education programs should focus on raising the parents' awareness that such a philosophy is unacceptable in a child's upbringing. Furthermore, it should be emphasized that having good communication skills, spending time as family and being a good role model is important. Parent education programs have shown some promise in reducing the risk for child abuse.

The second important step is to raise the awareness of the educators and administrators in school. School based programs are important because if educators and administrators have a raised awareness, they will be able to help law enforcement agencies in identifying abuse victims which in turn will enable law enforce agencies to take legal action in a timely manner.

If the carefully laid out plan for the above mentioned programs are carefully followed no doubt it would be a big step in the right direction. If we raise awareness of parents and educators and manage to prevent abuse before it even starts it will increase the quality of life for parents and the children. It should not be forgotten that children are the most innocent and vulnerable victims that we as members of the law enforcement agencies are here to protect.

\section{References}

Akers, R. L. \& Sellers, C. S. (2004). Criminological Theories: Introduction, Evaluation, And Application (4th ed.). Los Angeles: Roxbury.

Bersani, C. A. \& Chen, Huey-Tsyh (1988). Sociological Perspectives In Family Violence. In Van Hasselt, V. B., Morrison, R. L., Bellack, A. S., and Hersen, M. (eds.), Handbook of Family Violence Plenum Press, New York, pp. 51-86. 
Kargin, V. (2016). Consequences of child maltreatment in society and implementation of new prevention policies. International Journal of Human Sciences, 13(1), 1984-1996. doi:10.14687/ijhs.v13i1.3747

Child Abuse Prevention and Treatment Act as Amended by the Keeping Children and Families Safe Act of 42 U.S.C. 5101-5116et seq. (2003).

Child Abuse and Domestic Violence Report (2010). Turkey Ministry of Families and Social Policies. Directorate General for Child Services. Ankara.

Coulton, C. J., Crampton, D. S., James. M. I., Spilsbury, C. \& Korbin, J.E. (2007). How Neighborhoods Influence Child Maltreatment: A Review Of The Literature And Alternative Pathways. Child Abuse and Neglect, 31(11-12), 1117-1142.

Coulton, C. J., Korbin. J. E., Lindstrom-Ufuti, H. \& Spilsbury, J. (2000). Neighborhood Views On The Definition And Etiology Of Child Maltreatment Child Abuse and Neglect, 24(12), 15091527.

Coulton, C. J., Korbin, J. E., \& Su, M. (1999). Neighborhoods And Child Maltreatment: A MultiLevel Study. Child Abuse andNeglect, 23(11), 1019-1040.

English, D. (1998). The Extent And Consequences Of Child Maltreatment. The Future of Children, $8(1), 39-53$.

Fergusson, D. M., Horwood, L. J., \& Lynskey,M. T. (1996). Childhood Sexual Abuse And Psychiatric Disorder In Young Adulthood: II. Psychiatric Outcomes Of Childhood Sexual Abuse. Journal of the American Academy of Child and Adolescent Psychiatry, 35(10), 1365-1374.

Fergusson, D. M. \& Lynskey, M. T. (1997). Physical Punishment/Maltreatment During Childhood And Adjustment In Young Adulthood. Child Abuse and Neglect, 21(7), 617-630.

Finkelhor, D. (1994). Current Information On The Scope And Nature Of Child Sexual Abuse. The Future of Children, 4(2), 31-53.

Finkelhor, D., Kendall-Tackett K. A. \& Williams, L. M.(1993).Impact of Sexual Abuse on Children: A Review and Synthesis of Recent Empirical Studies. Psychological Bulletin, 113(1),164-180.

Famularo, R., Kinsheriff, R., \& Fenton, T. (1992). Parental Substance Abuse And The Nature Of Child Maltreatment. Child Abuse and Neglect, 16(4), 475-483.

Gelles, R . J., \& Straus, M. A. (1979). Violence In The American Family. Journal of Social Issues, 35(2), 15-39.

Gokler, I. (2002). Child Abuse And Neglect: Effect Of Early Stress On Neurobiological Development. Turkish Journal of Child and Adolescent Mental Health, 9, 47-57.

Grand Jury Report of Altoona https://www.attorneygeneral.gov/uploadedFiles/MainSite/Content/Related_Content/Pre ssReleases/GJ\%20Diocese\%20Report.pdf

Gumus, S. Y. http://www.milliyet.com.tr/cocuk-Istismari-Ve-Etkileri-Pembenar-Yazardetay-Aile1299265/

Gutierres, S. E. \& Van Puymbroeck, C. (2006). Childhood And Adult Violence In The Lives Of Women Who Misuse Substances. Aggression and Violent Behavior: A Review Journal, 11(5), 497513.

Herrenkohl, Todd I., Huang, Bu, Tajima, Emiko A., Whitney \& Stephen D. (2003). Examining the Link between Child Abuse and Youth Violence: An Analysis of Mediating Mechanisms. Journal of Interpersonal Violence 18: 1189-1208.

Herrenkohl, R. C., Egolf, B. F. \& Herrenkohl, C. (1997). Preschool Antecedents of Adolescent Assaultive Behavior: A Longitudinal Study. American Journal of Orthopsychiatry, 67(3), 422-432.

Hirschi, T. (1969). Causes of Delinquency. Los Angeles: University of California Press.

Huefner, J. C., Ringle, J. L., Chmelka, M. B. \& Ingram, S. D. (2007). Breaking the Cycle of Intergenerational Abuse: The Long-Term Impact Of A Residential Care Program. Child Abuse and Neglect, 31(2), 187-199. 
Kargin, V. (2016). Consequences of child maltreatment in society and implementation of new prevention policies. International Journal of Human Sciences, 13(1), 1984-1996. doi:10.14687/ijhs.v13i1.3747

Jaudes, P. K., Ekwo, E. \& Van Voorhis, J. (1995). Association of Drug Abuse And Child Abuse. Child Abuse and Neglect, 19(9), 1065-1075.

Kara, B., Bicer, U. \& Gokalp, A. S. (2004). Child Abuse. The Journal of Child Health and Diseases, 47, 140-151.

Malinosky-Rummel, R., \& Hanen, D. J. (1993). Long-Term Consequences Of Childhood Physical Abuse. Psychological Bulletin, 114(1), 68-79.

Pelcovitz, D., Kaplan, S. J., DeRosa, R. R., Mandel, F. S., \& Salzinger, S. (2000). Psychiatric Disorders In Adolescents Exposed To Violence And Physical Abuse. American Journal of Orthopsychiatry, 70(3), 360-369.

Sherwood, T. (2015). Encyclopedia of Diversity and Social Justice. Rowman and Littlefield, New York.

Simsek, F., Ulukol, B., \& Bingoler, B. (2004). Child Abuse and Neglect: A Review. The Journal of Forensic Science, 3(1), 47-52.

Sidebotham, P., \& Hweon, J. (2006). Child Maltreatment in the 'Children of the Nineties': A Cohort Study of Risk Factors. Child abuse and neglect, 30(5), 497-522.

Sutherland, E. H. (1947). Principles of Criminology (4th ed.). Philadelphia: J.B. Lippincott.

Tackett, K. K. (2002). The Health Effects Of Child Abuse: Four Pathways By Which Abuse Can Influence Health. Child Abuse and Neglect, 26, 715-729.

Taner, Y. \& Gokler, B. (2004). Child Abuse And Neglect: Psychiatric Aspects. Hacettepe Medical Journal, 35(2), 82-86.

Tarde, G. (1912). Penal Philosophy. Translated by R. Howell. Boston, MA: Little,Brown.

Tirasc1, Y. \& Goren, S. (2007). Child Abuse And Neglect. Dicle Medical Journal, 34(1), 70-74.

Tjaden, P. \& Thoennes, N. (2000). Full Report Of The Prevalence, Incidence, And Consequences Of Violence Against Women. U.S. Department Of Justice. Office of Justice Programs. National Institute of Justice. Retrieved on February 29, 2012 from https://www.ncjrs.gov/pdffiles1/nij/183781.pdf

Turkish Statistical Institute. Juveniles Received Into Security Units (2013). Turkish Statistical Institute, Printing Division, Ankara. Available at: http://www.turkstat.gov.tr

U.S. Department of Health Human Service. Administration for Children, Youth and Families. Child Maltreatment (2005). Washington, D.C.: Government Printing Office. Available at: www.acf.hhs.gov.

U.S. Department of Health and Human Services, Administration on Children, Youth, and Families. Child Maltreatment (2008). Washington, D.C.: Government Printing Office. Available at: www.acf.hhs.gov.

Widom, C. S. \& Maxfield, M. G (2001). An Update on the "Cycle of Violence.” Washington, DC: U.S. National Institute of Justice.

Warr, M. (2001). The Social Origins Of Crime: Edwin Sutherland And The Theory Of Differential Association. In Paternoster, R., \& Bachman, R. (Eds). Explaining Criminals and Crime. Los Angeles, CA: Roxbury Publishing Company.

Welsh, C. B. \& Senna, J.J. \& Siegel, J.L. (2003). Juvenile Delinquency. ( $8^{\text {th }}$ edition). Belmont, CA: Thomason.

Widom, C. S., Schuck, A. M., \& White, H. R. (2006). An Examination Of Pathways From Childhood Victimization To Violence: The Role of Early Aggression and Problematic Alcohol Use. Violence and victims, 21(6), 675-690.

Widom, C. S. (1998) Child Abuse, Neglect, and Adult Behavior. American Journal of Orthopsychiatry, 59 (3), 355-367. 
Kargin, V. (2016). Consequences of child maltreatment in society and implementation of new prevention policies. International Journal of Human Sciences, 13(1), 1984-1996. doi:10.14687/ijhs.v13i1.3747

\section{Appendix}

\section{Physical and Behavioral Indicators of Child Abuse and Neglect}

\begin{tabular}{|c|c|c|}
\hline $\begin{array}{|ll|}\text { Type } & \text { of } \\
\text { Abuse } & \\
\end{array}$ & Physical Indicators & Behavioral Indicators \\
\hline $\begin{array}{l}\text { Physical } \\
\text { Abuse }\end{array}$ & $\begin{array}{l}\text { - Unexplained bruises (in various } \\
\text { stages of healing) } \\
\text { - Unexplained burns, especially } \\
\text { cigarette burns or immersion } \\
\text { burns } \\
\text { - Unexplained fractures, } \\
\text { lacerations or abrasions } \\
\text { - Swollen areas or delayed or } \\
\text { - Evidence of } \\
\text { inappropriate treatment for } \\
\text { injuries }\end{array}$ & $\begin{array}{l}\text { - Self-destructive } \\
\text { - Withdrawn and/or aggressive - behavioral extremes } \\
\text { - Arrives at school early or stays late as if afraid to be } \\
\text { at home } \\
\text { - Chronic runaway (adolescents) } \\
\text { - Complains of soreness or moves uncomfortably } \\
\text { - Wears clothing inappropriate to weather, to cover } \\
\text { body } \\
\text { - Bizarre explanation of injuries } \\
\text { - Wary of adult contact }\end{array}$ \\
\hline $\begin{array}{l}\text { Physical } \\
\text { Neglect }\end{array}$ & $\begin{array}{l}\text { - Abandonment } \\
\text { - Unattended medical needs } \\
\text { - Consistent lack of supervision } \\
\text { - Consistent hunger, } \\
\text { inappropriate dress, poor } \\
\text { hygiene } \\
\text { - Lice, distended stomach, } \\
\text { emaciated } \\
\text { - Inadequate nutrition }\end{array}$ & $\begin{array}{l}\text { - Regularly displays fatigue or listlessness, falls asleep } \\
\text { in class } \\
\text { - Steals food, begs from classmates } \\
\text { - Reports that no caretaker is at home } \\
\text { - Frequently absent or tardy } \\
\text { - Self-destructive } \\
\text { - School dropout (adolescents) } \\
\text { - Extreme loneliness and need for affection }\end{array}$ \\
\hline $\begin{array}{l}\text { Sexual } \\
\text { Abuse }\end{array}$ & \begin{tabular}{|l||} 
Sexual abuse may be non-touching: \\
obscene language, pornography, exposure \\
- or touching: fondling, molesting, oral \\
sex, intercourse \\
- Torn, stained or bloody \\
underclothing \\
- Pain, swelling or itching in \\
genital area \\
- Difficulty walking or sitting \\
- Bruises or bleeding in genital \\
- Vrea \\
- Venereal disease \\
infections \\
\end{tabular} & $\begin{array}{l}\text { - Excessive seductiveness } \\
\text { - Role reversal, overly concerned for siblings } \\
\text { - Massive weight change } \\
\text { - Suicide attempts (especially adolescents) } \\
\text { - Inappropriate sex play or premature understanding } \\
\text { of sex } \\
\text { - Threatened by physical contact, closeness }\end{array}$ \\
\hline $\begin{array}{l}\text { Emotional } \\
\text { Abuse }\end{array}$ & \begin{tabular}{|l|} 
Emotional abuse may be name-calling, \\
insults, put-downs, etc., or it may be \\
terrorization, isolation, humiliation, \\
rejection, corruption, ignoring \\
- Speech disorders \\
- Delayed physical development \\
- Substance abuse \\
- Ulcers, asthma, severe allergies
\end{tabular} & $\begin{array}{l}\text { - Habit disorder (sucking, rocking, biting) } \\
\text { - Antisocial, destructive } \\
\text { - Neurotic traits (sleep disorders, inhibition of play) } \\
\text { - Passive and aggressive - behavioral extremes } \\
\text { - Delinquent behavior (especially adolescents) } \\
\text { - Developmentally delayed }\end{array}$ \\
\hline
\end{tabular}

Adapted from the Children Welfare Information Gateway retrieved in 2016 from https://www.childwelfare.gov/topics/can/identifying/ 